Original Article

\title{
Effect of 12-month rehabilitation with low loading program on chronic respiratory disease
}

\author{
Yasuhiro Endo, RPT, PhD ${ }^{1)^{*}}$, Kunio Dobashi, MD ${ }^{2)}$, Daisuke Uga, RPT, MS ${ }^{1,2)}$, \\ Daigo Kato, RPT, MS ${ }^{1,2)}$, Rie Nakazawa, RPT, PhD ${ }^{2)}$, Masaaki Sakamoto, RPT, PhD $^{2)}$, \\ Makoto Fueki, MD ${ }^{3)}$, Sohei Makino, $\mathrm{MD}^{3)}$ \\ 1) Department of Rehabilitation, Jobu Hospital for Respiratory Diseases: 586-1 Taguchi, Maebashi, \\ Gunma 371-0048, Japan \\ 2) Graduate School of Health Sciences, Gunma University, Japan \\ 3) Respiratory Medicine, Jobu Hospital for Respiratory Diseases, Japan
}

\begin{abstract}
Purpose] The purpose of this study was to examine the effect of 12-month rehabilitation with low loading program on chronic respiratory disease. [Subjects and Methods] Twelve patients with chronic respiratory disease participated in this study, in which the effect of long-term rehabilitation for 12 months was assessed. Nine patients had chronic obstructive pulmonary disease, two had asthma, and one had interstitial pneumonia. In all patients, symptoms, lower-extremity strength, walking distance, activities of daily living, and quality of life were investigated to examine the effect of respiratory rehabilitation. [Results] After 12 months, the isometric knee extension strength and weight-bearing index both showed a significant increase. [Conclusion] The findings of this study suggested that improvement in lower-limb muscle strength can be achieved through long-term intervention, and indicated the validity of repetitive standing and walking exercises.

Key words: Respiratory rehabilitation, Long-term intervention, Effect of intervention
\end{abstract}

(This article was submitted Nov. 17, 2015, and was accepted Dec. 15, 2015)

\section{INTRODUCTION}

Chronic obstructive pulmonary disease (COPD) is a common chronic respiratory disease, and its prevalence rate and mortality are both increasing. The number of patients with a COPD diagnosis in Japan is about 210,000; however, there may be 5,300,000 persons with COPD according to the Nippon COPD Epidemiology study ${ }^{1)}$. According to the Global Initiative for Chronic Obstructive Lung Disease guideline ${ }^{2}$, the objective of COPD management is to relieve symptoms, prevent and treat exacerbations, improve the health status and exercise tolerance of patients, and prevent comorbidities. Rehabilitation is considered one of the important treatments for $\mathrm{COPD}^{2,3}$.

Dyspnea is the main symptom of a chronic respiratory disease such as COPD, and the activities of daily living (ADL) are gradually compromised by the progression of dyspnea. Patients can fall into a vicious circle in which physical activity declines, disuse syndrome occurs, and exacerbation of dyspnea follows. Many persons with COPD also have psychological symptoms such as depression and insecurity ${ }^{4-6}$. These psychological symptoms also have a marked influence on the quality of life (QOL) of patients with chronic respiratory disease. Therefore, the target of rehabilitation is to free patients from the vicious circle by maintaining and improving their ADL, QOL, and physical activity. Many studies have shown that improvement in exercise tolerance, ADL, and QOL can be achieved by means of respiratory rehabilitation, and it is assigned a high level of evidence in COPD guidelines ${ }^{2,3}$. However, the effect of long-term respiratory rehabilitation on COPD is still controversial, as the duration of intervention has generally been limited to 6-12 weeks in studies of rehabilitation by physiotherapists $^{7-10}$. Accordingly, we examined the effect of long-term rehabilitation that was performed more than once a

*Corresponding author. Yasuhiro Endo (E-mail: m11712009@gunma-u.ac.jp)

(C2016 The Society of Physical Therapy Science. Published by IPEC Inc.

This is an open-access article distributed under the terms of the Creative Commons Attribution Non-Commercial No Derivatives (by-nc-nd) License $<$ http://creativecommons.org/licenses/by-nc-nd/4.0/>. 
month for 12 months by physiotherapists in patients with chronic respiratory disease.

\section{SUBJECTS AND METHODS}

Twelve patients with chronic respiratory disease were recruited from the rehabilitation program by physiotherapists at our hospital and participated in this study. Nine patients had COPD, two had asthma, and one had interstitial pneumonia. The patients comprised of 10 men and 2 women, with an average age of $69.8 \pm 8.1$ years. Lung function tests showed the following results: vital capacity (VC), $3.4 \pm 1.2 \mathrm{~L}$; \%VC, $101.7 \pm 20.0 \%$; forced expiratory volume (FEV) $1.0 \%, 55.6 \pm$ $32.7 \%$; and $\% \mathrm{FEV}$ in $1 \mathrm{~s}, 48.3 \pm 25.0 \%$.

All participants signed a consent form after the study procedures were explained to them in detail. This study was carried out in accordance with the Declaration of Helsinki and was approved by the ethics committee of Jobu Hospital for respiratory disease (approval no. 20120523).

The following outcome measures and tests were investigated and conducted: height, weight, body mass index (BMI), Medical Research Council dyspnea scale, isometric knee extension strength, strength to body weight-bearing index (WBI), 6-min walking test, Nagasaki University Respiratory ADL questionnaire (NRADL), St George's Respiratory Questionnaire (SGRQ), and COPD assessment test (CAT). The isometric knee extension strength was measured by using a handheld dynamometer (HHD; Anima Corp, $\mu$-tas F-1). The subjects were tested while sitting on a table with the trunk upright and the knee joint in $90^{\circ}$ flexion. They were instructed to push against a force plate with maximal effort for approximately $5 \mathrm{~s}$, and the peak torque was recorded. Measurement was done twice in both legs, and the higher of the two measurements for each leg was selected for analysis. The WBI was calculated as a subject's maximum isometric muscle strength divided by the body weight. Measurements were performed at the start of the intervention and after 12 months of rehabilitation.

The rehabilitation program used in this study was designed for patients with severe muscle weakness and low exercise tolerance, and is expected to be continued for a long period. When patients visited the hospital, they performed knee extension exercises in the sitting position and repetitive standing to increase lower-extremity muscle strength, as well as walking, relaxation including breathing exercises, guidance on the correct breathing method, and ADL practice under a physiotherapist's supervision. The patients were asked to perform the same program every day at home, except on the day of an outpatient visit. The rehabilitation program on each day was conducted for 30-40 min. The exercises and the loading amount of muscle strength were decided from the results of the first evaluation. Subjects for whom standing was difficult did the knee extension exercises in the sitting position, and those who could stand up easily did repetitive standing. Stand training was performed for three sets of 15 times. The walking training involved continuous walking for $10 \mathrm{~min}$; however, it was stopped if symptoms of desaturation and dyspnea became aggravated in the subjects. The frequency of performing rehabilitation ranged from twice a week to once every 2 months, depending on the subject.

The findings obtained before and after the intervention were compared by using the Wilcoxon signed-rank test. Spearman's correlation coefficient analysis was employed to examine the relation among the changes in weight, BMI, and WBI. All statistical analyses were carried out by using SPSS 16.0 software for Windows (SPSS Inc., Chicago, IL, USA), and significance was accepted if the p-value was $<0.05$.

\section{RESULTS}

The results of measurements before and after the intervention are shown in Table 1. The average frequency of rehabilitation in all subjects was $1.9 \pm 1.4$ times per month (range, 1.5-4.5 times). Comparison of data between before intervention (baseline) and after 12 months demonstrated a significant decrease in both body weight and BMI. The isometric knee extension strength and WBI increased significantly on both sides. There were no significant changes in the other variables.

There was a significant correlation $(\mathrm{r}=0.996)$ between the change in body weight and the change in BMI. However, there was no significant correlation between the change in weight and the change in WBI (Table 2).

\section{DISCUSSION}

In patients with chronic respiratory diseases such as COPD, long-term rehabilitation has been reported to help achieve an increase in the walking distance, improvement in the QOL, an increase in exercise tolerance, a decrease in hospitalization frequency, and a decrease in acute exacerbation ${ }^{7-9,11)}$; however, evaluations of its effectiveness have shown varying results. The effect of a long-term respiratory rehabilitation program lasting for $>12$ weeks is higher than that of a short-term program according to the American College of Chest Physicians/American Association of Cardiovascular and Pulmonary Rehabilitation guideline ${ }^{3)}$. However, there have been no reports about pulmonary rehabilitation programs used by physiotherapists lasting for $>6-12$ weeks. Chaincharn et al. ${ }^{12)}$ reported that unsupervised training for 12 months after direct intervention by a physiotherapist for 3 months led to improvement in muscle strength, endurance, the 6-min walking distance, dyspnea, and QOL, and that the effects were still maintained at 24 months; however, the effect of direct intervention by physiotherapists for $>3$ months has not been investigated before.

The present study revealed that the isometric knee extension strength and WBI were both increased at 12 months com- 
Table 1. Comparison between data before intervention (baseline) and the findings after 12 months

\begin{tabular}{lccc}
\hline & Baseline & After 12 months & \\
\hline Height (cm) & $162.3 \pm 10.2$ & $162.4 \pm 10.0$ & \\
Weight (kg) & $60.0 \pm 9.6$ & $58.6 \pm 9.3$ & $* *$ \\
BMI & $22.5 \pm 3.2$ & $22.0 \pm 3.0$ & $*$ \\
MRC & $1.8 \pm 1.3$ & $1.8 \pm 1.1$ & \\
Knee extension strength/ Rt & $27.6 \pm 10.8$ & $35.9 \pm 13.8$ & $* *$ \\
Knee extension strength/ Lt & $28.0 \pm 10.1$ & $34.1 \pm 14.7$ & $*$ \\
WBI/ Rt & $0.469 \pm 0.195$ & $0.619 \pm 0.242$ & $* *$ \\
WBI/ Lt & $0.476 \pm 0.189$ & $0.580 \pm 0.212$ & $*$ \\
6MWT (m) & $439.6 \pm 111.8$ & $437.9 \pm 107.4$ & \\
NRADL (points) [0-100] & $91.3 \pm 10.5$ & $92.8 \pm 14.8$ & \\
SGRQ-symptom [0-100] & $48.3 \pm 28.5$ & $39.0 \pm 20.4$ & \\
SGRQ-activity [0-100] & $34.6 \pm 21.2$ & $38.4 \pm 26.0$ & \\
SGRQ-impact [0-100] & $13.9 \pm 14.1$ & $16.2 \pm 18.9$ & \\
SGRQ-total [0-100] & $25.7 \pm 16.9$ & $26.5 \pm 19.4$ & \\
CAT (points) [0-40] & $11.4 \pm 8.1$ & $13.9 \pm 9.6$ & \\
\hline
\end{tabular}

Data are shown as mean $\pm \mathrm{SD}$.

BMI: body mass index; MRC: Medical Research Council dyspnea scale; Rt: right; Lt: left; WBI: weight-bearing index; 6MWT: 6-min walking test; NRADL: Nagasaki University Respiratory Activities of Daily Living Questionnaire; SGRQ: St George's Respiratory Questionnaire; CAT: COPD assessment test

$* * \mathrm{p}<0.01, * \mathrm{p}<0.05$

Table 2. Correlation between changes in BMI or WBI and body weight

\begin{tabular}{lllll}
\hline & & \multicolumn{2}{c}{$\mathrm{r}$} \\
\hline Change of BMI vs. change of weight & & 0.926 & $* *$ \\
& $\mathrm{Rt}$ & 0.116 & \\
Change of WBI vs. change of weight & $\mathrm{Lt}$ & 0.310 & \\
\hline
\end{tabular}

BMI: body mass index; WBI: weight-bearing index

$* * \mathrm{p}<0.01$

pared with those at baseline. Weight and BMI decreased; however, there was no significant correlation between the changes in WBI and weight. Therefore, the increase in WBI was due to an increase in the muscle strength and was not secondary to weight loss.

The rehabilitation program used in this study was designed for patients with severe muscle weakness and low exercise tolerance, and is expected to be continued for a long period. When patients visited the hospital, they performed repetitive standing and breathing exercises and underwent continuous walking training, under the physiotherapist's supervision. Moreover, they were asked to perform the same program every day at home, except on the day of an outpatient visit.

The increase in muscle strength in the legs after this intervention is thought to be related to repetitive standing and continuous walking training. Exercise tolerance was lower with this program than that achieved with treadmill and ergometer exercises in previous reports ${ }^{13}$; however, the exercise tolerance achieved was suitable for patients who had severe muscle weakness at the baseline evaluation, and the program resulted in an adequate improvement in muscle strength. According a meta-analysis of the prolonged effect of rehabilitation, exercise tolerance is maintained after the end of the rehabilitation program $^{14)}$. In the present study, many patients also showed improvement in or maintenance of the 6-min walking distance 12 months later. The results of the NRADL, SGRQ, and CAT showed the same trend. Therefore, our long-term intervention program can be considered effective for maintaining exercise tolerance, ADL, and QOL in patients with chronic respiratory disease.

Beckerman et al. ${ }^{15)}$ reported that during inspiratory muscle training for 1 year in patients with significant COPD, there was an increase in exercise capacity, improvement in the QOL, and decrease in dyspnea. However, the contents of the program in that study were different from those in our study. The results of the study by Beckerman et al. ${ }^{15)}$ showed that improvement in the breathing function contributes to the improvement in movement ability. Furthermore, the results of this research showed that an intervention for increasing leg muscle strength and exercise tolerance directly leads to those improvements. The program used in this study included whole-body movements such as standing and walking, which are among the usual 
movements in daily living. Patients with chronic respiratory disease often have dyspnea and inability to perform these movements. Therefore, a program including daily-life movements is easy to implement in the rehabilitation of elderly patients with chronic respiratory disease, and can become a motivation for treatment. An easy-to-implement program that does not require a tool can also be continued easily at home, which may be a factor for improvement.

After the initial period of rehabilitation, only a few patients continued to perform rehabilitation by themselves at home because many of them had no exercise habit or motivation to perform exercise. To deal with this problem, patients should be directly involved in long-term ongoing respiratory rehabilitation, even if the frequency of intervention is decreased.

In this study, we evaluated the effect of rehabilitation through a comparative evaluation of patients before intervention and after 12 months of intervention. Considering the chronic course of COPD, a long-term clinical trial should be designed to assess the protective effect of ongoing pulmonary rehabilitation on the ADL and QOL covering several years.

\section{REFERENCES}

1) Fukuchi Y, Nishimura M, Ichinose M, et al.: COPD in Japan: the Nippon COPD Epidemiology study. Respirology, 2004, 9: 458-465. [Medline] [CrossRef]

2) Global Initiative for Chronic Obstructive Lung Disease: Global strategy for the diagnosis, management, and prevention of chronic obstructive pulmonary disease, NHLBI/WHO Workshop Report, national Heart, Lung and Blood Institute, Bethesda, 2001 (Update2014). GOLD website: www.goldcopd.com, 2014.

3) Ries AL, Bauldoff GS, Carlin BW, et al.: Pulmonary rehabilitation: joint ACCP/ AACVPR evidence-based clinical practice guidelines. Chest, 2007, 131: 4S-42S. [Medline] [CrossRef]

4) Jones PW, Baveystock CM, Littlejohns P: Relationships between general health measured with the sickness impact profile and respiratory symptoms, physiological measures, and mood in patients with chronic airflow limitation. Am Rev Respir Dis, 1989, 140: 1538-1543. [Medline] [CrossRef]

5) Kaneda R, Sunjyu H, Iguchi A, et al.: Factors that impact anxiety and depression in patients with 162 chronic obstructive pulmonary disease. J Phys Ther Sci, 2011, 23: 927-931. [CrossRef]

6) Iwai S, Senjyu H, Kaneda R, et al.: Personality traits of patients with chronic obstructive pulmonary disease who exhibit depression. J Phys Ther Sci, 2010, 22: 93-99. [CrossRef]

7) Engström CP, Persson LO, Larsson S, et al.: Long-term effects of a pulmonary rehabilitation programme in outpatients with chronic obstructive pulmonary disease: a randomized controlled study. Scand J Rehabil Med, 1999, 31: $207-213$. [Medline] [CrossRef]

8) Griffiths TL, Burr ML, Campbell IA, et al.: Results at 1 year of outpatient multidisciplinary pulmonary rehabilitation: a randomised controlled trial. Lancet, 2000, 355: 362-368. [Medline] [CrossRef]

9) Foglio K, Bianchi L, Ambrosino N: Is it really useful to repeat outpatient pulmonary rehabilitation programs in patients with chronic airway obstruction? A 2-year controlled study. Chest, 2001, 119: 1696-1704. [Medline] [CrossRef]

10) Chigira $Y$, Takai $T$, Oda $T$, et al.: Difference in the effect of outpatient pulmonary rehabilitation due to variation in the intervention frequency: intervenetion centering on home-based exercise. J Phys Ther Sci, 2014, 26: 1041-1044. [Medline] [CrossRef]

11) Güell R, Casan P, Belda J, et al.: Long-term effects of outpatient rehabilitation of COPD: a randomized trial. Chest, 2000, 117: 976-983. [Medline] [CrossRef]

12) Pothirat C, Chaiwong W, Phetsuk N, et al.: Long-term efficacy of intensive cycle ergometer exercise training program for advanced COPD patients. Int J Chron Obstruct Pulmon Dis, 2015, 10: 133-144. [Medline] [CrossRef]

13) Casaburi R, Patessio A, Ioli F, et al.: Reductions in exercise lactic acidosis and ventilation as a result of exercise training in patients with obstructive lung disease. Am Rev Respir Dis, 1991, 143: 9-18. [Medline] [CrossRef]

14) Cambach W, Wagenaar RC, Koelman TW, et al.: The long-term effects of pulmonary rehabilitation in patients with asthma and chronic obstructive pulmonary disease: a research synthesis. Arch Phys Med Rehabil, 1999, 80: 103-111. [Medline] [CrossRef]

15) Beckerman M, Magadle R, Weiner M, et al.: The effects of 1 year of specific inspiratory muscle training in patients with COPD. Chest, 2005, 128: 3177-3182. [Medline] [CrossRef] 